\title{
A DUPLA SUBNOTIFICAÇÃO DO CRIME DE ES- TUPRO DE VULNERÁVEL DURANTE A PANDEMIA POR COVID-19 NO BRASIL
}

\section{THE DOUBLE UNNOTIFICATION OF THE VULNE- RABLE RAPE CRIME DURING THE COVID-19 PAN- DEMIC IN BRAZIL}

Cinthya Maria Caetano Albuquerque ${ }^{1}$

\begin{abstract}
Resumo: O crime de estupro vel. Destarte, o artigo tem como de vulnerável ocorre quando a objetivo principal compreender vítima é incapaz de consentir os aspectos socias e jurídicos do relação sexual, já que não confenômeno da subnotificação de segue oferecer resitência. Para estupro de vulnerável durante se efetivar o estupro, não é necessário que ocorra a conjunção a pandemia por COVID-19 no Brasil. Trata-se de uma pesquisa carnal, já que atos libidinosos, de natureza básica, cujo método tais como o toque em genitálias de abordagem utilizado foi o intambém são considerados para dutivo, com análise qualitativa e a configuração do crime. A pesquantitativa, desenvolvida atraquisa justifica-se por analisar a vés dos procedimentos técnicos influência que o isolamento social causou para a subnotificação dos casos de estupro de vulneráde documentação próprios da pesquisa bibliográfica e documental. Entre os resultados obti-
\end{abstract}

$1 \quad$ Universidade Estadual Vale do Acaraú - UVA

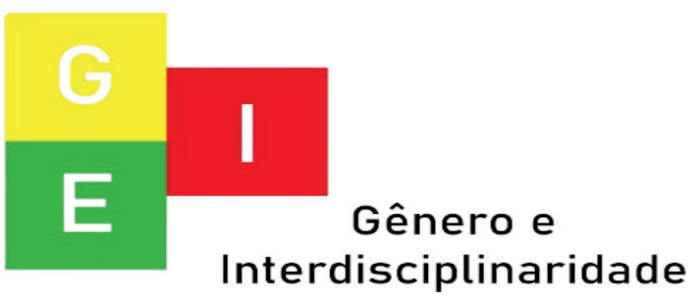


ISSN: $2675-7451$

Vol. 02 - n 05 - ano 2021

Editora Acadêmica Periodicojs

dos, considerou-se, enfim, que a the vulnerable occurs when the pandemia por COVID-19 tornou victim is unable to consent to seas vítimas de estupro, especialxual intercourse, since he is unamente os vulneráveis, ainda mais suscetíveis à prática do crime, ao passo que a subnotificação destes casos cresceu, pois o crime ocorre em maioria no ceio intrafamiliar, em um contexto de isolamento social. É necessário, então, que se desnaturalize a cultura do estupro e a sexualização infantil, bem como sejam criadas políticas públicas efetivas para a proteção dos infantes, de forma a incentivar e possibilitar o acesso à justiça, além de disseminar amplo conhecimento sobre os direitos das crianças e adolescentes.

Palavras-chave: Estupro de vulnerável. Isolamento social. Subnotificação. Pandemia por COVID-19.

Abstract: The crime of rape of ble to offer resistance. To make rape effective, it is not necessary for the carnal conjunction to occur, since libidinous acts, such as touching genitals, are also considered for the configuration of the crime. The research is justified by analyzing the influence that social isolation has caused for the underreporting of cases of rape of the vulnerable.Thus, the article has as main objective to understand the social and legal aspects of the phenomenon of underreporting of rape of the vulnerable during the COVID-19 pandemic in Brazil. It is a research of a basic nature, whose method of approach used was inductive, with qualitative and quantitative analysis, developed through the technical procedures of documentation specific to bibliogra-

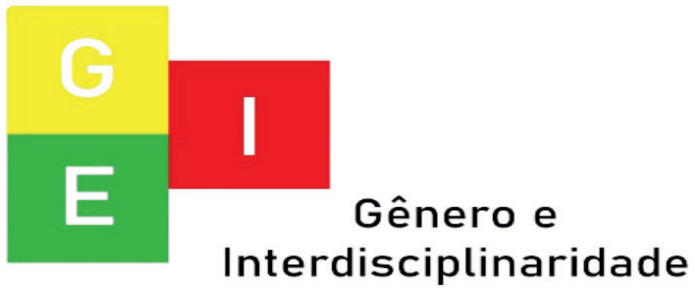


Vol. 02 - n 05 - ano 2021

Editora Acadêmica Periodicojs

phic and documentary research.

Among the results obtained, it was considered, finally, that the COVID-19 pandemic made victims of rape, especially vulnerable ones, even more susceptible to the practice of crime, while the underreporting of these cases grew, as the crime occurs in majority in the intrafamily supper, in a context of social isolation. It is necessary, then, to denaturalize the culture of rape and child sexualization, as well as to create effective public policies for the protection of infants, in order to encourage and enable access to justice, in addition to disseminating broad knowledge about the rights of children. children and adolescents.

Keywords: Rape of the vulnerable. Social isolation. Underreporting. Pandemic by COVID-19.

\section{INTRODUÇÃO}

No Brasil, existem relevantes problemáticas em diversos segmentos que requerem estritas análises jurídicas com forte teor empírico a fim de possuir total compreensão dos fatos e traçar meios mais efetivos para abordagem das problemáticas. O estupro de vulnerável tem sido uma questão cada vez mais abrangente e próxima da realidade de muitos.

Primordialmente, haverão conceituações do estupro e os seus pontos de extensão como consequência do ato em se tratar de um crime propulsor de inúmeras outras naturezas as quais a violência compete. Posteriormente, ficará em destaque alguns grupos sociais em específico, que são as crianças e os adolescentes como alguns dos mais suscetíveis ao crime de violência sexual por

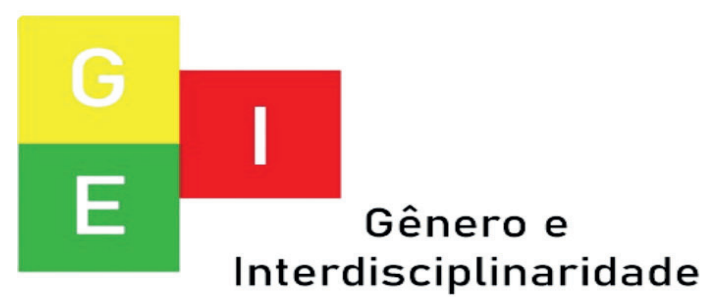


ISSN: $2675-7451$

Vol. 02 - n 05 - ano 2021

Editora Acadêmica Periodicojs

seu alto grau de vulnerabilidade.

Em um cenário de normalidade, são inúmeras as dificuldades que as vítimas enfrentam para fazer a denúncia do crime desditoso. Haja vista que a cultura do estupro como processo arraigado socialmente que, por sua vez vem tendo suas raízes ainda mais fincadas e repleto de concepções inconsistentes. Além da subnotificação nos números de casos como grande enfoque na dimensão da problemática em haver casos de estupro com aumento na frequência, sobretudo sendo tratados de maneira omissa e negligenciada, durante o isolamento social ocasionando pela pandemia por COVID-19.

O objetivo geral do presente artigo é compreender os aspectos sociais e jurídicos do fenômeno da subnotificação de estupro de vulnerável durante a pandemia por COVID-19 no Bra- sil. Além de possuir como objetivos específicos: perpassar a perspectiva do estupro de modo geral e suas abrangências; demonstrar a vulnerabilidade como ponto consternador em casos de abuso de cunho sexual; abordar a intervenção do Direito nos casos de estupro de vulneráveis; transmitir a percepção e a problemática na queda da taxa de denúncias de estupro na pandemia do coronavírus; apresentar que a subnotificação não diz respeito à coarctação no número de casos.

Destarte, a pesquisa propõe uma natureza básica, por procurar compreender uma problemática social e transpassar esse entendimento de modo a acrescentar ao aprendizado. $\mathrm{O}$ método científico utilizado foi o indutivo, já que observa os acontecimentos da sociedade e sua problematização fomentando chegar em concepções e possíveis

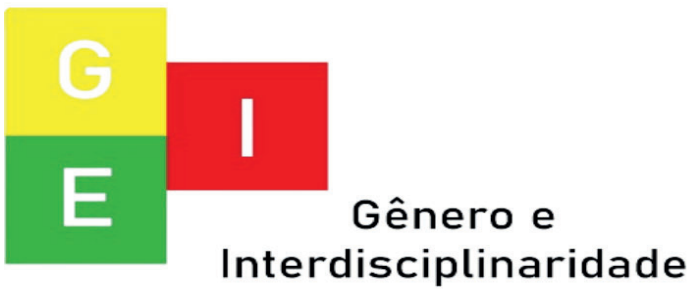


conclusões. O seu objeto de estudo foi o explicativo, por tentar disseminar as concepções adquiridas de maneira simples e clara. E os procedimentos utilizados foram o bibliográfico e documental, visto que sua abrangência é resultado de um embasamento fundamentado em análises de perspectivas e contribuições já relatadas.

CONCEITUAÇÃO DE ESTUPRO DE VULNERÁVEL

A violência, cada vez mais, tem se tornado um problema de saúde pública. A natureza dessa problemática, segundo a Organização Mundial da Saúde (OMS) pode ser de várias esferas, como física, sexual, psíquica, além de privações e negligência. Em relação ao estupro de vulnerável, a violência se específica quanto ao cunho sexual que, por sua vez, pode promover nas demais naturezas. Além de um grave problema de saúde pública, constitui um crime irascível reconhecido como um desafio social (OLIVEIRA et al, 2014). Gerando assim, muitas vezes, danos piscologicos, como o transtorno de estresse pós-traumático, advindos de um estupro. Conforme afirma Mattar (2007, p. 549):

A violência sexual pode gerar outras consequências, como problemas familiares e sociais, abandono dos estudos, perda do emprego, separação conjugal, abandono da casa e prostituição, como parte dos problemas psicossociais relacionados a essa dinâmica.

O Código Penal, em seu artigo 213 configura o estupro como sendo o ato de constranger alguém, mediante violência ou

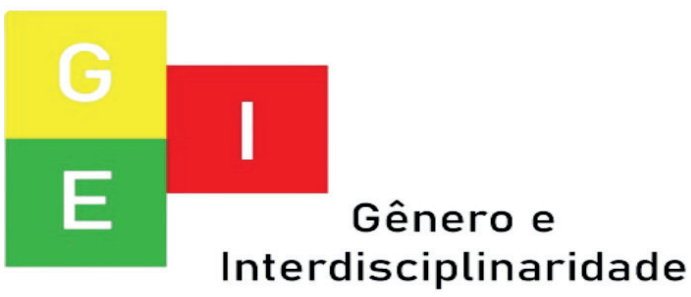


ISSN: 2675-7451

Vol. 02 - n 05 - ano 2021

Editora Acadêmica Periodicojs

grave ameaça, a ter conjunção carnal ou a praticar ou permitir que com ele se pratique outro ato libidinoso (BRASIL, 2009). Dentro desse conceito, está incluída como conjunção carnal (penetração peniana ou de outro objeto no ânus, vagina ou boca), independentemente da orientação sexual ou do sexo da pessoa/vítima.

A violência sexual é a forma coercitiva para conseguir qualquer tipo de relação com o intuito de conseguir vantagens de cunho sexual, até mesmo por comentários ou investidas. Portanto, ela viola a dignidade da vítima por meio da força, intimidação ou violência psicológica.

Para a caracterização do estupro de vulnerável, segundo o artigo 217-A, a vítima deve ser menor de 14 anos, se encontar enferma ou possuir alguma deficiência mental, não portando necessário discernimento para a prática do ato. $\mathrm{O}$ legislador, também considerou estupro de vulnerável, qualquer outra causa quando a vítima não consegue oferecer resistência, como é o caso da ingestão de drogas, ou bebidas alcólicas.

Vale ressaltar que, mesmo que haja consentimento à prática sexual de uma vítima menor de 14 anos, tendo em vista sua eventual experiência sexual anterior ou a existência de relacionamento amoroso entre o agente e a vítima, não afastam a ocorrência do crime. Foi o decidido pelo Supremo Tribunal de Justiça (STJ) em 2012, na Súmula 593 que dispõe sobre estupro de vulnerável.

Desse modo, é mister relatar a perspectiva do Ministério da Saúde (2012, p. 58) ao transpassar que a violência sexual é quando:

Ocorrem situações de estupro, abuso incestuoso, assédio

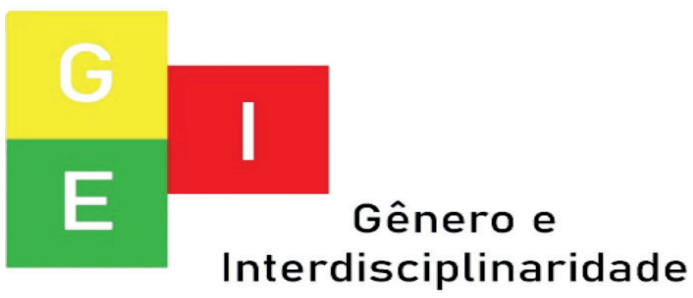


ISSN: 2675-7451

Vol. 02 - n 05 - ano 2021

Editora Acadêmica Periodicojs

sexual, sexo forçado no casamento, jogos sexuais e práticas eróticas não consentidas, impostas, pornografia infantil, pedofilia, voyeurismo; manuseio, penetração oral, anal ou genital, com pênis ou objetos, de forma forçada. Inclui, também, exposição coercitiva/ constrangedora a atos libidinosos, exibicionismo, masturbação, linguagem erótica, interações sexuais de qualquer tipo e material pornográfico.

Essa realidade de pessoas que usam a força, comentários ou qualquer outra forma a fim de possuir algum benefício de cunho sexual sem quaisquer consentimentos, tem crescido de maneira expressiva. Os casos estão onde menos pode-se esperar, como na casa do vizinho ou até mesmo dentro da própria casa. É uma questão extremamente complexa, por abranger muitos segmentos que, às vezes, são negligenciados ou omissos pelos próprios membros da família quando o ato é no convívio pessoal.

VULNERABILIDADE DE CRIANÇAS E ADOLESCENTES

Vulnerabilidade destaca-se como sendo a situação de fragilidade, o que ocorre quando algo ou alguém fica isento de certos amparos que a competem, seja com seu desenvolvimento social, seja com sua segurança e vários outros segmentos. Segundo Capez (2015), vulnerável será qualquer pessoa que não tenha capacidade para consentir com a prática sexual, por se encontrar em alguma situação de perigo ou

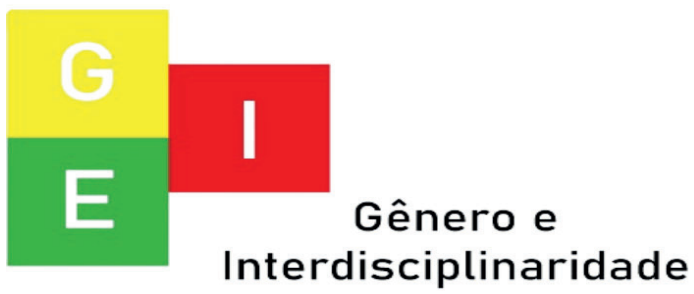


ISSN: 2675-7451

Vol. 02 - n 05 - ano 2021

Editora Acadêmica Periodicojs

fragilidade.

Dentre muitos personagens que podem vir a ser suscetíveis ao evento contemporâneo, destacam-se as crianças e os adolescentes, por além de estarem em grande porcentagem em relação populacional total do país, também são os que estão em grande processo de desenvolvimento psicossocial.

Essa vulnerabilidade quanto as crianças e os adolescentes voltada para a questão do abuso sexual é altamente preocupante pelas proporções as quais as taxas desse fato têm alarmado. Ademais, vale ressaltar, a sujeição que esse grupo social tem ficado, pois muitas vezes precisarem ficar longe dos pais, e não possuem total compreensão e susceptibilidade a fim de uma eventual autoproteção. Segundo Nunes e Sales (2016, p. 11), “muitos são os grupos vulneráveis aos vários tipos de violência, dentre eles o estupro, todavia destaca-se a população infanto-juvenil, devido às características peculiares."

Muitos são os períodos do processo de desenvolvimento psicossocial. A criança, até os seus doze anos, ainda está no terceiro período, o qual compete ao período das operações completas. Portanto, até que a mesma possua o mais elevado período de desenvolvimento, necessitará de um longo processo (PLATT, 2018). Para que ela perceba toda uma situação de moléstia ou algo do gênero, e consiga compreender seu perigo iminente a ponto de tentar barrar o ocorrido, é visivelmente algo laborioso.

Na adolescência, embora corresponda ao quarto período do desenvolvimento, não significa pressupor total capacidade do adolescente em saber lidar

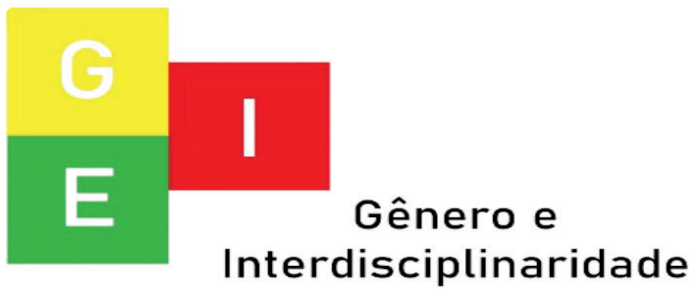


ISSN: 2675-7451

Vol. 02 - n 05 - ano 2021

Editora Acadêmica Periodicojs

com problemáticas, sobretudo de cunho sexual. É um período de constantes mudanças bioquímicas, sociais, emocionais (ZAMBON, 2012). Todo esse processo repercute na complexidade em um adolescente lidar com situações desafiadoras, as tornando também alvos fáceis e vulneráveis.

Segundo Romero (2007, p. 20) "em todo o mundo, as crianças vêm sendo vítimas das mais variadas formas de violência. A pior destas formas de violência é aquela sofrida dentro de suas próprias casas". As crianças nem sempre são protegidas por aqueles que lhes deveriam dar amor e anteparo e devido a sua vulnerabilidade acabam sofrendo. É dever da família, da sociedade e do Estado assegurar à criança e ao adolescente, com absoluta prioridade, o direito à vida, à saúde, à educação, à dignidade, ao res- peito, à liberdade, além de colocá-los a salvo de toda forma de exploração, violência e opressão.

\section{CULTURA DE ESTUPRO NO} BRASIL

Chamar uma determinada prática social de cultura, implica atribuir-lhe uma série de fatores que exprimem que essa conduta caracteriza-se, entre outras coisas, por ser algo feito de maneira corriqueira e não listado como raras exceções, colocando essa ação como uma atividade humana. Dessa forma, o crime de estupro representa um cerne muito complexo, mas que ainda é discutido de uma maneira superficial. Algo paradoxal, já que é comum diariamente encontrar em reportagens e noticiários, diversos relatos de estupro. Assim, como aponta Araújo (2020, p. 24), “o estupro é o único crime

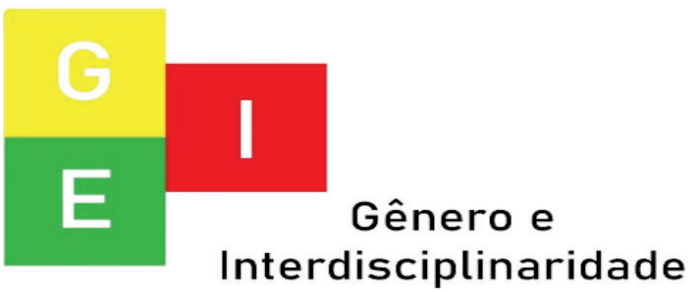


Vol. 02 - n 05 - ano 2021

Editora Acadêmica Periodicojs

no qual são as vítimas que sentem vergonha, mesmo depois de anos ou décadas."

Vale ressaltar, que o estupro é enraizado por uma cultura de culpabilização e a ignorância acerca dos problemas por ela passados. Nesse aspecto, a vítima é ensinada a tomar cuidados para não ser assediada ou violentada física ou psicologicamente; e, em contraponto, o meio fiscalizador se ocupa em buscar formas de justificar a violência sofrida (SANTOS E ALVES, 2015). Fazendo com que frases como "o que você estava fazendo na rua a essa hora e com essa roupa?" e "você tem certeza que foi estupro mesmo?" sejam consideradas normais e, portanto, passíveis de repetição constante, gerando nas vítimas o sentimento de humilhação.

O silenciamento, e a não denúncia do crime sofrido, também possuem como motivo a dependência financeira ao agressor, como nos casos de crianças e mulheres ou mulheres que toleram os maridos que abusam dos filhos. Acrescenta-se a essa lista a descrença no poder público, e na morosidade de processos desse tipo. É esse o desabafo de Fernanda, e tantas outras vítimas que passaram por situações semelhantes: "Sofri violência do estupro em si, das instituições públicas, que deveriam me acolher, e por fim, da sociedade, da qual eu também não esperava" (ARAÚJO, 2020, p. 54).

Existem ainda, diversos mitos que constroem a figura do típico estuprador como sendo "um homem mentalmente perturbado que usa da força para violentar mulheres honestas e descuidadas." (SOUZA, 2017, p. 20). O que na maioria dos casos, não representa a realidade obser-

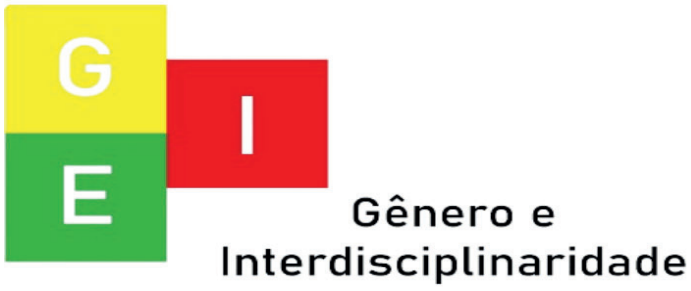


ISSN: 2675-7451

Vol. 02 - n 05 - ano 2021

Editora Acadêmica Periodicojs

vada, já que segundo o Instituto

Patrícia Galvão (2016), em cerca de $75,9 \%$ dos casos, as vítimas possuem algum vínculo com os abusadores. Sejam eles pais, padrastos, irmãos, babás, tios ou conhecidos.

Retratando, de uma maneira direta, que não somente os homens sejam estupradores, nem que todos os seres humanos sejam diretamente responsáveis pela prática do estupro, mas que, de muitas maneiras, a cultura do machismo e da misoginia contribui para a perpetuação desse tipo de violência focada, principalmente, contra o sexo feminino, que representa a maioria das vítimas do estupro.

Segundo o Anuário da Segurança Pública, em 2018 no Brasil, foram notificados 967 casos de estupros cometidos por mulheres, uma taxa de $1,9 \%$ do total. E outros 1,8\% foram de pessoas estupradas por uma mulher e um homem juntos. Entre os alvos dos estupros cometidos por pessoas do sexo feminino, são em geral as mais fracas fisicamente, principalmente crianças de ambos os sexos e pessoas com deficiência, ou impossibilitadas de reagir por qualquer motivo, como uma doença imcapacitante ou grave.

Ademais, a cultura do estupro se constitui desde o ceio intrafamiliar, quando as vítimas de estupro são menores de 14 anos de idade. Pessoas que não sabem como se defender, e não entendem que gestos, beijos forçados e carícias se constituem como abuso, e não como uma forma de demonstrar carinho. Pois, os casos de abuso sexual contra crianças e adolescentes quando notificados, tendem a serem crônicos e já possuirem um longo tempo de duração. Acarre-

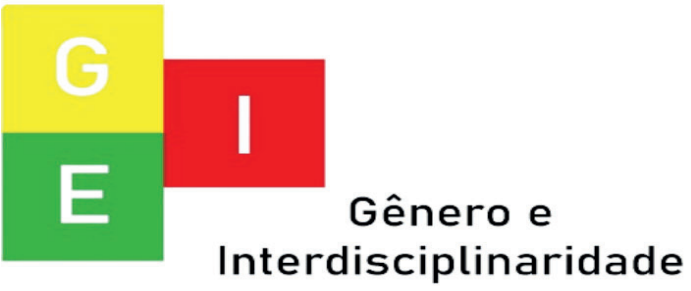


ISSN: 2675-7451

Vol. 02 - n 05 - ano 2021

Editora Acadêmica Periodicojs

tando em danos físicos e traumas psicológicos, como ansiedade, depressão, culpa ou até mesmo, medo de se relacionarem com outras pessoas.

\section{SUBNOTIFICAÇÃO DOS}

CASOS DE ESTUPRO DE VULNERÁVEL DURANTE A PANDEMIA POR COVID-19

O Brasil, país de grande extensão territorial, apresenta importantes desigualdades econômicas, sociais e culturais, porém o estupro desvela essa heterogeneidade, visto que o fenômeno acontece em todas as camadas sociais e independe da raça, classe, religião ou cultura. A subnotificação nos casos de estupro, e especialmente, estupro de vulnerável, surgiu pelo silenciamento sistêmico arraigado culturalmente e pela desinformação.
De acordo com os dados

de pesquisa realizada em 2013, pelo Instituto de Pesquisa Ecônomica Aplicada (IPEA), estima-se que a cada ano no Brasil 0,26\% da população sofre violência sexual, o que indica que haja anualmente 527 mil tentativas ou casos de estupros consumados no país, dos quais $10 \%$ são reportados à polícia. Ou seja, uma porcentagem baixíssima para um crime de natureza tão grave. Uma das justificativas para essa baixa taxa de notificações é o julgamento, o medo de morte, sentimento de culpa e o constrangimento como consequência do crime.

Analisando os dados e estatísticas referentes aos meninos e meninas, mais da metade dos que são molestados $(53,6 \%)$ tem no máximo treze anos. E ampliando mais um pouco essa faixa etária, há $71,8 \%$ com até dezessete anos que são vítimas

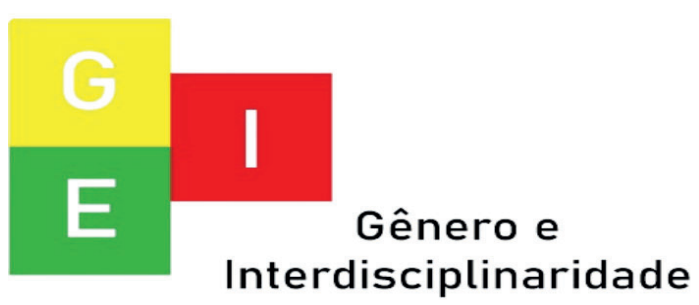


ISSN: 2675-7451

Vol. 02 - n 05 - ano 2021

Editora Acadêmica Periodicojs

de estupro. Apesar de as vítimas serem em sua maioria do sexo feminino, ligadas a condição de ser mulher na sociedade com as diversas maneiras relacionadas à persistência do sistema patriarcal (ABREU et al, 2020).

No caso da justificativa quanto aos meninos, aponta-se os fatores culturais, e estigmas relacionados ao sexo masculino. Observa-se a maior demanda desses casos para os serviços de média e alta complexidade de saúde, para o atendimento emergencial, em detrimento dos serviços especializados no acolhimento e suporte social e judiciário. Por outro lado, não se pode menosprezar as altas proporções de crianças do gênero masculino vítimas de estupro, principalmente a partir dos seis anos de idade (OLIVEIRA et al, 2014).

Diante de um cenário atípico causado pela pandemia por COVID-19, em que as pessoas necessitam ficar em isolamento social para evitar a propagação do vírus, aumenta-se o risco das pessoas vulneráveis sofrerem de abuso sexual. Isso porque elas começam a conviver durante mais tempo com os seus possíveis agressores.

Conforme o Fórum Brasileiro de Segurança Pública (FBSP), em 2020 houvera uma queda de $23,8 \%$ nos casos de estupro, e de $22,4 \%$ nos casos de estupro de vulnerável, comparando-se com o mesmo período do ano passado em todos os estados do Brasil. Em números absolutos, apesar da queda, a quantidade de casos contra os vulneráveis, ainda se mostra assustadora. Sendo 17.287 notificações neste ano, em comparação com as 22.282 denúncias do primeiro semestre de 2019.

Porém, essa redução

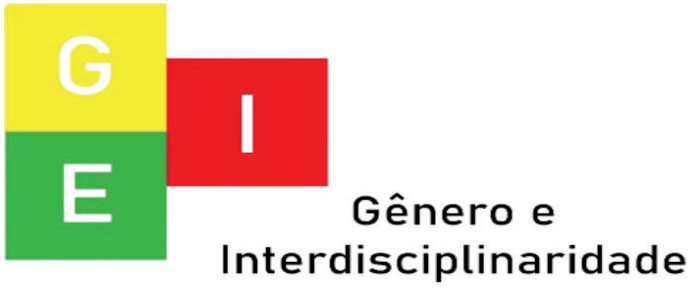


Vol. 02 - n 05 - ano 2021

Editora Acadêmica Periodicojs

não significa que a ocorrência desse crime diminuiu, já que por conta do isolamento social causado pela pandemia da COVID-19 no Brasil, as denúncias que chegavam por meio de professores, cuidadores e profissionais de saúde, se extinguiram com o fechamento de creches e escolas, locais em que certos indícios, como mudanças de comportamento, ou o auxílio de psicólogos, revelam que essas crianças ou adolescentes, sofrem algum tipo de abuso sexual em suas casas. Segundo Schaw (2020), a queda do número de denúncias do crime de estupro de vulnerável:

É preocupante porque indica que a subnotificação pode estar muito maior do que sempre foi. Em períodos como este não é comum explodirem as denúncias, até porque a vítima está presa com o agressor. Sair desse contexto e conseguir denunciar é difícil, ainda mais para uma criança.

A redução dos números, não é um bom sinal, ao contrário, é preocupante pois indica que há subnotificação dos casos no período crítico da pandemia, onde a população passa por um rígido isolamento, em que as crianças continuam sem chances e meios para denunciar. Sair desse contexto e conseguir denunciar é difícil, ainda mais para uma criança. A ameaça não se expressa no número de denúncias, mas na percepção de que a queda no acesso a delegacias, educadores, redes de proteção e órgãos públicos se reflete em um abuso silencioso, mas nem por isso inexistente.

O abuso infantil é decorrente do fato de as crianças, muitas vezes, não terem noção do

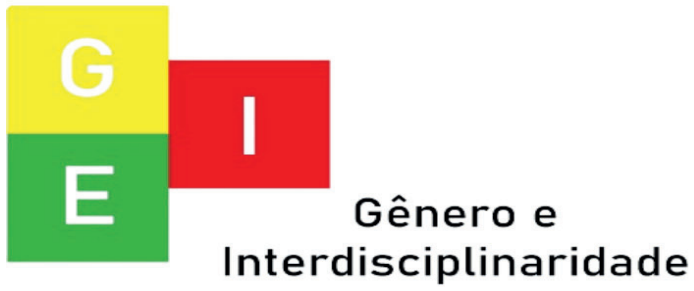


Vol. 02 - n 05 - ano 2021

Editora Acadêmica Periodicojs

que estão sofrendo. As crianças e

adolescentes tendem a confiar em

pessoas do seu ciclo familiar ou

de amizade e, quando a violência

sexual acontece, elas nem sequer

se dão conta de que aquilo é pro-

blemático. O lugar onde a crian-

ça deveria ser idealmente pro-

tegida é, também, o local onde,

possivelmente, ela será vitimada

(EFREM, 2017). E, muitas ve-

zes, sem ter a quem recorrer, vis- to que o depoimento da vítima

contra um agressor conhecido

tem a tendência de ser abafado,

para não "destruir a vida do es-

tuprador" que é, até mesmo, tido

como mais uma "vítima" da si-

tuação. As famílias não querem,

num primeiro momento, admitir

que aquela bestialidade possa ter

acontecido debaixo do seu teto.

Gráfico 1: Quantidade de denúncias do crime de estupro de vulnerável entre o ano de 2020 e primeiro trimestre de 2021 no Estado de São Paulo.

\section{Estupro de vulnerável}
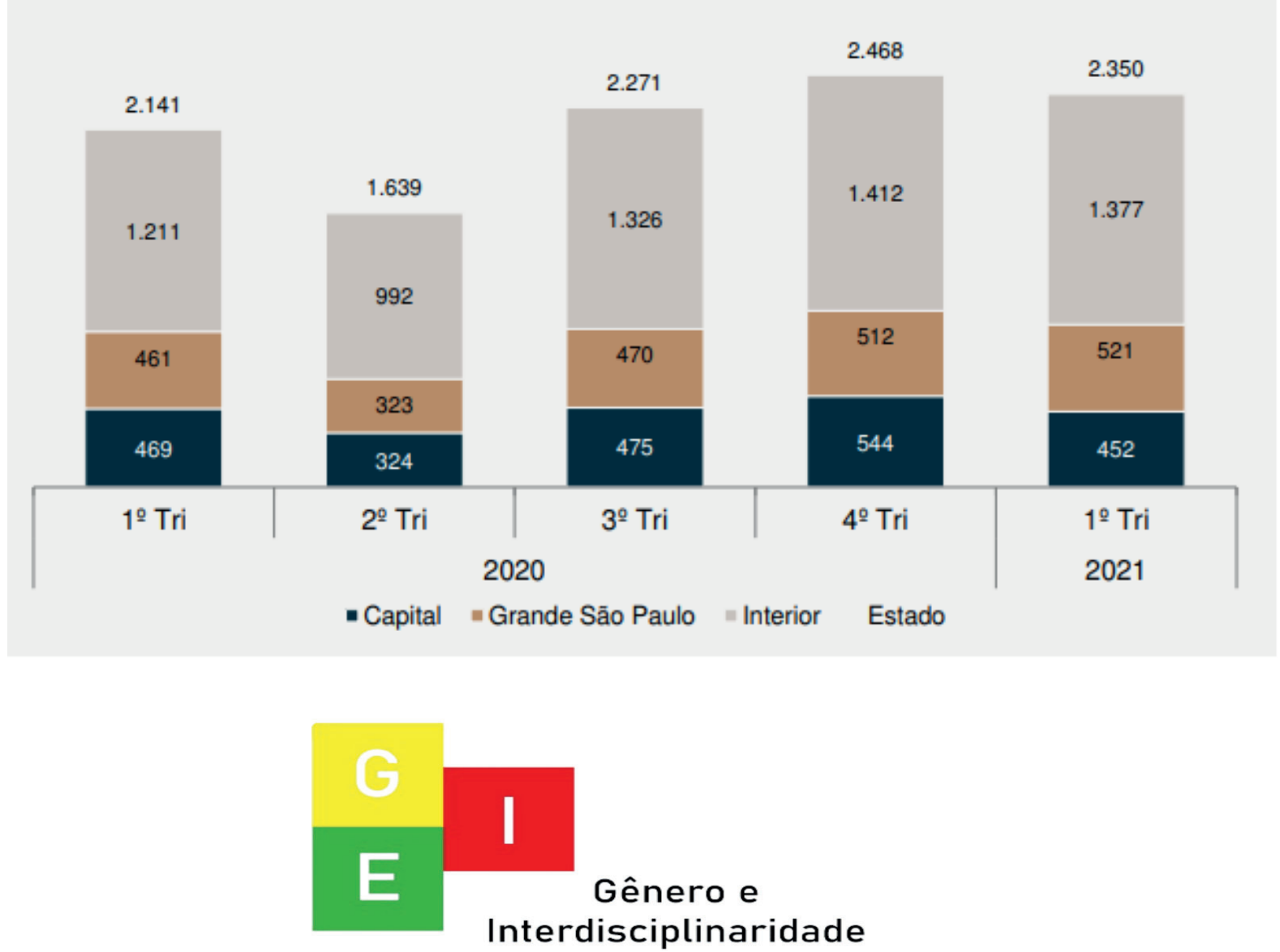
ISSN: $2675-7451$

Vol. 02 - n 05 - ano 2021

Editora Acadêmica Periodicojs

Fonte: Instituto Sou da Paz, 2021.

No primeiro semestre nos primeiros meses da crise de de 2020, período em que se inisaúde pública em 2020.

ciou a pandemia, a proporção de

Nossa hipótese - de crimes de violência contra crianque os estupros não diminuíram, ças e adolescentes, ocorridos em mas as denúncias sim - leva à residências do Estado de São triste constatação de que há um Paulo, foi de $84 \%$, tendo chegado grande número de meninas e mea $88 \%$ no mês de maio, superanninos que foram ou estão sendo do o patamar de $79 \%$ observado vítimas de violência sexual, oculao longo dos anos anteriores. Em tos pela ausência das denúncias sua maioria eram crianças e $75 \%$ (SOU DA PAZ, MPSP, Unicef, correspondiam a estupros regis2020, p. 41).

trados no Estado, no primeiro trimestre.

O estudo analisou da-

Segundo o relatório, feito pelo Ministério Público de São Paulo (MP-SP) em parceria com as denúncias de violência sexu-

o Fundo das Nações Unidas para al, sobretudo contra crianças e a Infância (Unicef) e o Instituto adolescentes menores de 14 anos, Sou da Paz (2020) a pandemia do caíram drasticamente no primeinovo coronavírus tem dificultado ro semestre de 2020. A grande as denúncias de estupros de vulmaioria das vítimas é do sexo feneráveis no estado de São Paulo, minino, com $83 \%$ das denúncias. que chegaram a cair quase $40 \% \quad$ Um dado interessante, é que o

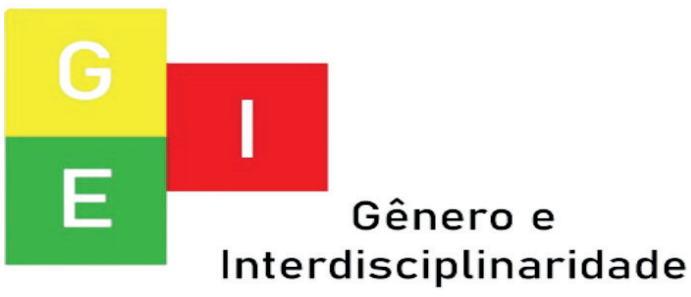


ISSN: 2675-7451

Vol. 02 - n 05 - ano 2021

Editora Acadêmica Periodicojs

pico de abuso entre os meninos ocorre entre 4 e 5 anos, enquanto o das meninas vem aos 13 anos. Em média, 7\% das vítimas possuem algum tipo de deficiência ou outra vulnerabilidade, sobressaindo a deficiência intelectual.

Outra informação relevante, é a subida do número de denúncias entre o $3^{\circ}$ e $4^{\circ}$ trimestre dos meses de 2020, que corresponderam ao período de reabertura econômica, e maior circulação de pessoas, e medidas menos rígidas em relação ao isolamento social. Porém, os números de denúncias de estupro de vulnerável voltam a cair a partir do $1^{\circ}$ trimestre de 2021 , quando o número de casos e óbitos voltaram a crescer (BRASIL, 2021), e foi necessário implementar novamente medidas de isolamento social rígida, fechamento de comércio e até mesmo escolas que começavam a receber os seus alunos de forma presencial (MONTEIRO, 2021).

$\mathrm{O}$ questionamento existente é se há uma relação proporcionalmente inversa entre o número de denúncias, e o isolamento social durante a pandemia do novo coronavírus: quando o número de denúncias sobe, as medidas de isolamento são mais flexíveis, quando elas voltam a cair, impera-se medidas de isolamento social mais restritivas.

É difícil mensurar como as sucessivas restrições e liberações sobre a circulação e o comércio têm afetado as ocorrências criminais e suas notificações às autoridades. No entanto, é perceptível que as dinâmicas dos diversos tipos de crimes foram afetadas de modo distinto pelas medidas de isolamento social, e portanto, é importante analisarmos as alterações nos índices criminais com cautela, já que repro-

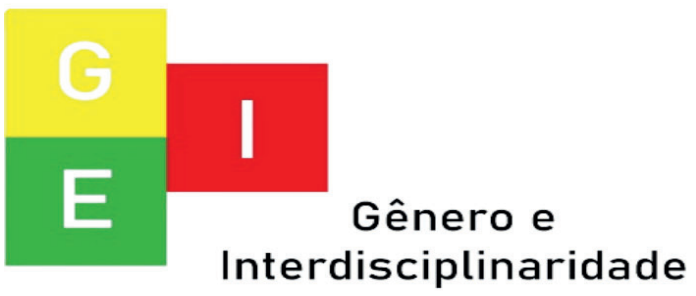


ISSN: $2675-7451$

Vol. 02 - n 05 - ano 2021

Editora Acadêmica Periodicojs

duzem não apenas as dinâmicas

criminais e de atuação das forças

policiais, mas também os efeitos

do isolamento social e diminui-

ção dos deslocamentos e ativida-

des em espaços públicos.

\section{CONSIDERAÇÕES FINAIS}

Ao final desse estudo, considerou-se, enfim, que a pandemia por COVID-19 tornou as vítimas de estupro, especialmente os vulneráveis, ainda mais suscetíveis à prática do crime, ao passo que a subnotificação destes casos cresceu, pois o crime ocorre em maioria no seio intrafamiliar, em um contexto de isolamento social.

Em um contexto de isolamento social, com a suspensão dos serviços regulares de educação e assistência que atendem crianças e adolescentes, justamente a população mais vulnerá- vel à violência sexual, é esperado que a subnotificação dos casos de estupros tenha um papel relevante nessa redução abrupta dos registros deste tipo de crime. Assim, é essencial uma análise mais refinada sobre o impacto do isolamento na subnotificação destes crimes, sobretudo aqueles que têm como vítimas vulneráveis, que representam $75 \%$ do total de vítimas de estupros no primeiro trimestre de 2021, e de que forma as denúncias destes crimes foram afetadas pelas medidas de isolamento social.

Uma estratégia importante para detecção de situações de vulnerabilidade é a capacitação de colaboradores que prestam serviços às crianças para que sejam capazes de identificar indícios de violação de direitos. E quando observados possam ser investigados e comunicados a toda a rede de proteção (unida-

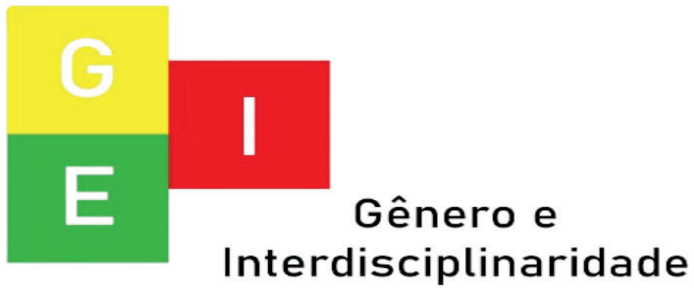


ISSN: $2675-7451$

Vol. 02 - n 05 - ano 2021

Editora Acadêmica Periodicojs

des de Saúde, Assistência Social, Analise especial do estupro em Educação, Direitos Humanos), adolescentes: características e para que se monitore e, quando impactos. Cogitare enferm. 24: necessário, aconteçam interven- e59743, 2019. Disponível em: htções.

tps://revistas.ufpr.br/cogitare/ar-

Existe um descaso em ticle/view/59743. Acesso em: 03 que as vítimas, quando contabi- Dez. 2020.

lizadas, são empilhadas em números, e dispostas, no máximo, em estatísticas, que, de tempos em tempos, chocam a opinião popular por seus números altamente elevados. É necessário, então, que se desnaturalize a cultura do estupro e a sexualização infantil, bem como sejam criadas políticas públicas efetivas para a proteção dos infantes, de forma a incentivar e possibilitar o acesso à justiça, além de disseminar amplo conhecimento sobre os direitos das crianças e adolescentes.

\section{REFERÊNCIAS}

ABREU, Paula Daniella de et al.

BRASIL. Superior Tribunal De Justiça. Agravo regimental no recurso especial: AgRg no REsp 1346774 SC, 2012/0205482-3. Rel. Ministro Marco Aurélio Bellizze, julgado em 18/12/2012. Disponível em: Acesso em: 14 maio 2021. Disponível em: https://www.stj.jus. br/docs_internet/revista/eletronica/stj-revista-sumulas-2017_46_ capSumulas593-600.pdf. Acesso em: maio 2021.

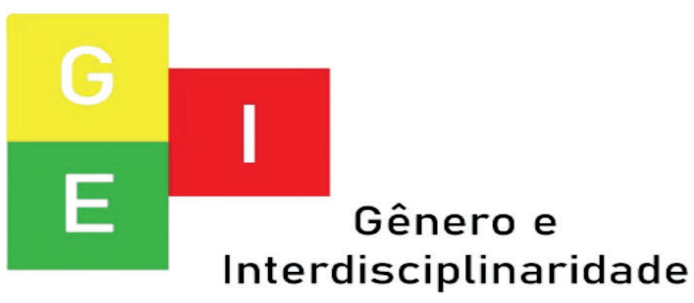


ISSN: 2675-7451

Vol. 02 - n 05 - ano 2021

Editora Acadêmica Periodicojs viva_instrutivo_violencia_inter-

BRASIL. Lei $\mathrm{n}^{\mathrm{o}}$ 12.015, de 7 de agosto de 2009. Altera o Título VI da Parte Especial do Decreto-Lei no 2.848 , de 7 de dezembro de 1940 - Código Penal, e o art. 1o da Lei no 8.072, de 25 de julho de 1990, que dispõe sobre os crimes hediondos, nos termos do inciso XLIII do art. 5 o da Constituição Federal e revoga a Lei n o 2.252, de 1 o de julho de 1954, que trata de corrupção de menores. Disponível em: http:// www.planalto.gov.br/ccivil_03/ ato2007-2010/2009/1ei/112015. htm. Acesso em: 09 dez. 2020.

BRASIL. Ministério da Saúde. Secretaria de Vigilância em Saúde. Viva: instrutivo de notificação de violência doméstica, sexual e outras violências. 2. ed. Brasília: Ministério da Saúde, 2016. Disponível em: http://bvsms.saude.gov.br/bvs/publicacoes/ pessoal_autoprovocada_2ed.pdf.

Acesso em: 16 dez. 2020.

BRASIL. Painel Coronavírus. Disponível em: https://covid.saude.gov.br/. Acesso em: 14 maio 2021.

CERQUEIRA, Daniel. Trajetórias individuais, criminalidade e o papel da educação. Disponível em: http://www.ipea.gov.br/atlasviolencia/artigo/9/trajetorias-individuais-criminalidade-e-o-papel-da-educacao. Acesso em: 16 dez. 2020.

EFREM, Roberto. A reivindicação da violência: gênero, sexualidade e a constituição da vítima. Cad. Pagu, Campinas, n. 50,175007, 2017 Disponível em: http://www.scielo.br/ scielo.php?script $=$ sci_arttexti4=83332017000200308-\&lng-

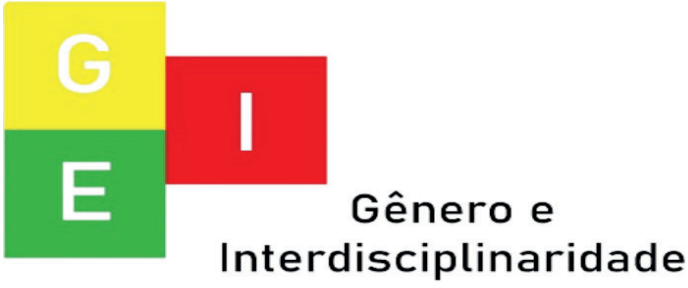


ISSN: 2675-7451

Vol. 02 - n 05 - ano 2021

Editora Acadêmica Periodicojs

en\&nrm. Acesso em 14 maio 2021.

FBSP. Anuário Brasileiro de Segurança Pública 2020. São Paulo, SP: Fórum Brasileiro de Segurança Pública, 2020.Disponível em: http://www.forumseguranca.org. br/publicacoes/anuario-brasileiro-de-seguranca-publica-2018/. Acesso em: 17 nov. 2020.

INSTITUTO PATRÍCIA GALVÃO. Percepções e comportamentos sobre violência sexual no Brasil. 2016. Disponível em: https://dossies.agenciapatriciagalvao.org.br/dados e fontes/ pesquisa/percepcoes e comportamentos sobre violencia sexual no brasil instituto patrícia galvão locomotiva 2016/. Acesso em: 17 nov. 2020.

IPEA. Estupro no Brasil: uma radiografia segundo os dados da Saúde. Brasília: Instituto de Pesquisa Econômica e Aplicada, 2014. Disponível em: file://C:/ Users/User/Downloads/IPEA_ Notatecnica_Estupro.pdf. Acesso em 17 nov. 2020.

MATTAR, Rosiane et al. Assistência multiprofissional à vítima de violência sexual: a experiência da Universidade Federal de São Paulo. Cadernos de Saúde Pública, Rio de Janeiro, v. 23, n. 2, p. 459-464, fev. 2007.

MONTEIRO, Daniel. São paulo terá toque de recolher e medidas mais rígidas de restrição a partir de 15 de março. Câmara Municipal de São Paulo, 2021. Disponível em: https://www.saopaulo. sp.leg.br/coronavirus/blog/sao-paulo-tera-toque-de-recolher-e-medidas-mais-rigidas-de-restricao-a-partir-de-15-de-marco/. Acesso em: 14 maio 2021.

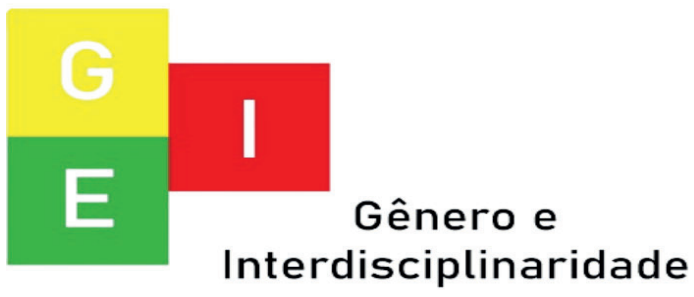


ISSN: 2675-7451

Vol. 02 - n 05 - ano 2021

Editora Acadêmica Periodicojs

shington: OMS, 2014. Disponível

NUNES, Antonio Jakeulmo, em:

SALES, Magda Coeli Vitori-

no. Violência contra crianças no

PLATT, Vanessa et al. Vio-

cenário brasileiro. Cienc. sau-

lência sexual contra crianças:

de colet. [Internet]. Disponível

autores, vítimas e consequen-

em: https://doi.org/10.1590/1413-

cias. Ciência \& Saúde Coleti-

81232015213.08182014. Acesso

va, 23(4):10119-1031, 2018. Dis-

em: 19 dez. 2020.

ponível em: https://www.

scielo.br/scielo.php?pid=S1413

OLIVEIRA, Jacqueline Reiter

$81232018000401019 \&$ script $=$ S-

de et al . Violência sexual e coo-

ci_abstract\&tlng=pt. Acesso em:

corrências em crianças e adoles-

19 dez. 2020.

centes: estudo das incidências

ao logo de uma década. Ciênc.

ROMERO, Karen Richter Pereisaúde coletiva, Rio de Janeiro , ra dos Santos. Crianças vítimas v. 19, n. 3, p.759-771, mar. 2014. de abuso sexual: aspectos psiDisponível em http://www.scielo. cológicos da dinâmica familiar. br/scielo.php?script=sci_arttexCuritiba/PR: Centro de Apoio t\&pid1232014000300759\&1nOperacional das Promotorias da $\mathrm{g}=\mathrm{pt \& nrm}=$ iso. Acesso em 14 Criança e do Adolescente. 2007. maio 2021.

Disponível em: https://crianca. mppr.mp.br/arquivos/File/publi/ ORGANIZAÇÃO MUNDIAL caopca/vitimas_de_abuso.pdf. DE SAÚDE. Informe mundial Acesso em: 14 maio 2021. sobre la violencia y la salud. Wa-

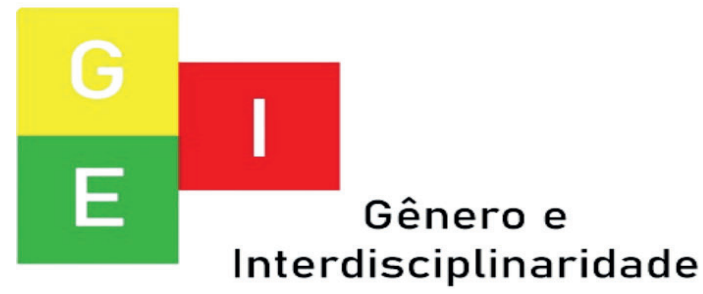


ISSN: 2675-7451

Vol. 02 - n 05 - ano 2021

Editora Acadêmica Periodicojs

SANTOS, Marcely Marques Honório; ALVES, Renata Farche. A cultura do estupro: banalização e visibilidade de mudanças através dos tempos. Ciência ET Praxis, v. 8, n. 16, p.51-55, 2015. Disponível em: http://revista. uemg.br/index.php/praxys/article/view/2223/1209. Acesso em: 17 dez. 2020.

SCHWAN, Carolina. Pandemia do coronavírus torna crianças mais expostas à violência. $\mathrm{O}$ vale. https://www. ovale.com.br/_conteudo/brasil/2020/08/112011-

pandemia-do-coronavirus-torna-criancas-mais-expostas-a-violencia.html. Acesso em: 14 maio 2021.

SOU DA PAZ. Boletim Sou da Paz Analisa $1^{\circ}$ trimestre de 2021. Instituto Sou da Paz, São Paulo. Disponível em: http:// soudapaz.org/o-que-fazemos/

conhecer/analises-e-estudos/

analises-e-estatisticas/boletim=-sou-da-paz-analisa/?showdocumentos\#4885. Acesso em: 14 maio 2021.

SOU DA PAZ; MPSP; UNICEF. Análise da ocorrência de estupro de vulnerável na cidade de São Paulo.

SOUZA, Renata Floriano de. Cultura do estupro: prática e incitação à violência sexual contra mulheres. Estudos Feministas, Florianópolis, 25(1): 422, janeiro-abril/2017. Disponível em: http://dx.doi.org/10.1590/ 1806-9584.2017v. Acesso em: 03 dez. 2020.

ZAMBON, Mariana Porto. Violência doméstica contra crianças e adolescentes: um desafio. Rev Assoc Med Bras, 2012;

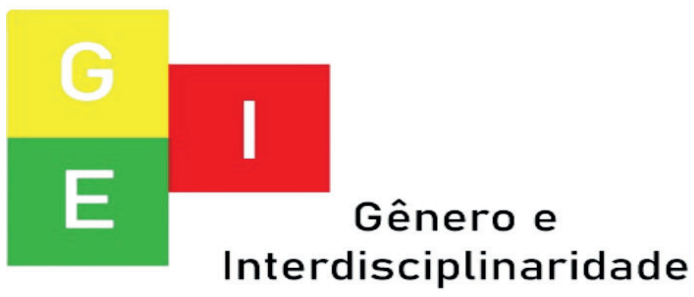


ISSN: 2675-7451

Vol. 02 - n 05 - ano 2021

Editora Acadêmica Periodicojs

58(4):465-471. Disponível em:

https://www.scielo.br/scielo.

php?script=sci_arttext\&pi-

$\mathrm{d}=\mathrm{S} 0104-42302012000400018$.

Acesso em: 03 dez. 2020.

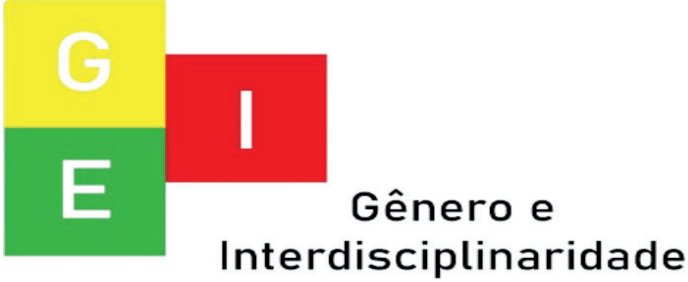

